EPJ Web of Conferences 98, 05002 (2015)

DOI: $10.1051 /$ epjconf/ 20159805002

(C) Owned by the authors, published by EDP Sciences - SIF, 2015

\title{
Thorium: An energy source for the world of tomorrow
}

\author{
J.-P. REVOL \\ Centro Studi e Ricerche "Enrico Fermi" - Roma, Italy and \\ International Thorium Energy Committee (iThEC) - Geneva, Switzerland
}

\begin{abstract}
Summary. - To meet the tremendous world energy needs, systematic R\&D has to be pursued to replace fossil fuels. Nuclear energy, which produces no green house gases and no air pollution, should be a leading candidate. How nuclear energy, based on thorium rather than uranium, could be an acceptable solution is discussed. Thorium can be used both to produce energy and to destroy nuclear waste. The thorium conference, organized by iThEC at CERN in October 2013, has shown that thorium is seriously considered by some major developing countries as a key element of their energy strategy. However, developed countries do not seem to move fast enough in that direction, while global cooperation is highly desirable in this domain. Thorium is not fissile. Various possible ways of using thorium will be reviewed. However, an elegant option is to drive an "Accelerator Driven System (ADS)" with a proton accelerator, as suggested by Nobel Prize laureate Carlo Rubbia.
\end{abstract}

\section{1. - Burning fossil fuel till the end?}

If, by the end of the 21st century, people in developing countries are allowed to live as well as people do in Europe today, the world power consumption will have to increase by a factor three or more. Europe is not representative of the world. It is one of the rare regions where the population is expected to decrease, there is little economic growth and the standard of living is the highest. Developing countries will determine the ecological future of the planet. Today, fossil fuels represent $87 \%$ of world primary energy consumption [1], and their consumption is still increasing, while resources are

This is an Open Access article distributed under the terms of the Creative Commons Attribution License 4.0, which permits unrestricted use, distribution, and reproduction in any medium, provided the original work is properly cited. 


\section{EPJ Web of Conferences}
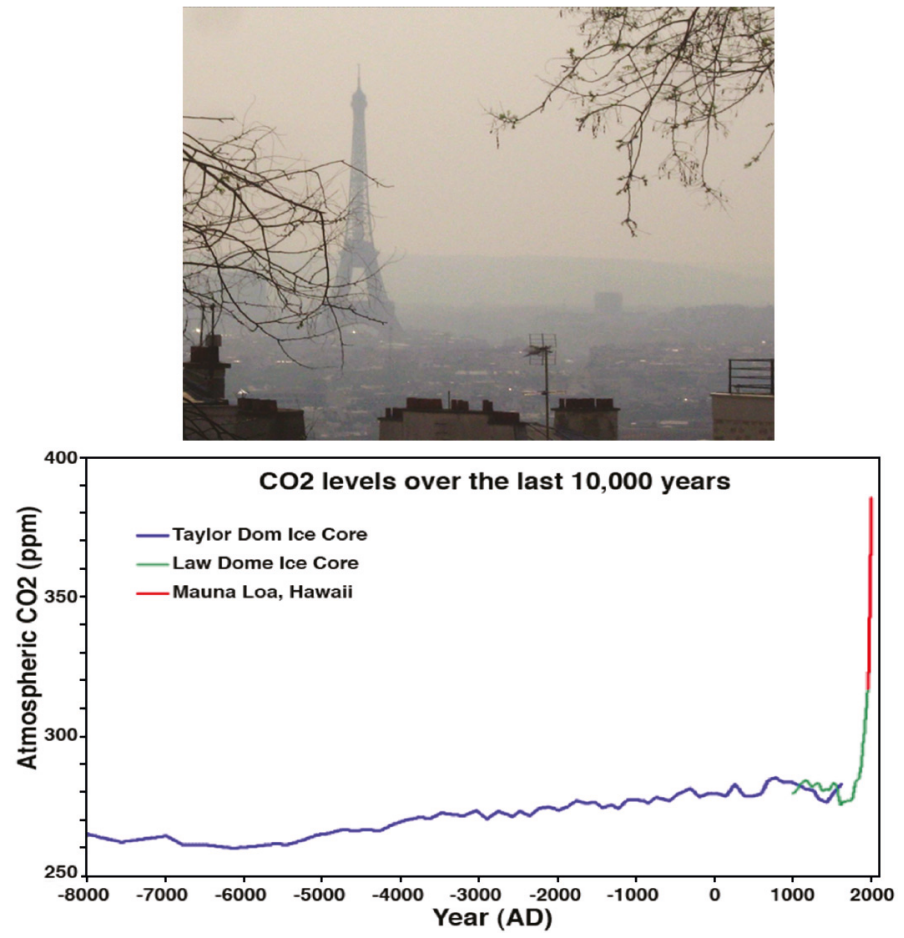

Fig. 1. - Top: Example of air pollution: photo of Paris, March 2014, reminiscent of Beijing (credit eknews09). Bottom: $\mathrm{CO}_{2}$ levels (parts per million) over the past 10000 years (Blue line from Taylor Dome ice cores (NOAA), green line from Law Dome ice core (CDIAC), red line from direct measurements at Mauna Loa, Hawaii (NOAA)).

finite. Even in countries strongly developing renewable energies, fossil fuel consumption remains high, as fossil fuels are used as backup when there is no wind or no sun.

There are at least three good reasons to replace fossil fuels for energy production and transportation:

- Their impact on global warming - according to a UCLA study [2], the atmospheric $\mathrm{CO}_{2}$ level is higher than ever in the past 15 million years (fig. 1 bottom), and increasing faster than ever before. Methane $\left(\mathrm{CH}_{4}\right)$ and nitrous oxide $\left(\mathrm{N}_{2} \mathrm{O}\right)$ follow similar trends. IPCC reported in March 2014 that by 2100, a global temperature increase larger than $2{ }^{\circ} \mathrm{C}$ is more likely than one of less than $2^{\circ} \mathrm{C}[3]$.

- Burning fossil fuel is having a severe impact on air pollution (fig. 1 top). Burning coal cost Europe alone 42.8 billion Euros in health care expenses in 2013 [4]. The ambient air pollution caused the premature death of more than 400000 Chinese in 2013. WHO reported that in 2012, around 7 million people died -1 in 8 of total global deaths — as a result of air pollution exposure [5]. 


\section{LNES 2014}

- At the present rate, fossil fuel will run out relatively quickly on the human time scale, with present reserve-to-production ratios of 53, 56 and 110 years [1], respectively for oil, gas and coal, while the current tendency is to increase fossil fuel consumption.

\section{2. - Energy R\&D}

Politicians will not invent the solution to the energy problem; it has to come from innovation. Innovation implies investment in both applied research and fundamental research. Without fundamental research there is no innovation.

In addition, the burden of energy $R \& D$ to replace fossil fuels should not be left to developing countries alone, because they cannot afford it, and furthermore, we should remember that we reached the level of wealth we enjoy today because we could use abundant and cheap fuel, without any concern for the environment. Our civilization is confined within a very thin breathing layer around the Earth that has to be carefully preserved through an organized and global effort.

Relying entirely on wind and solar energy is not realistic; at least not until the issue of the massive storage of electricity is resolved. Renewable energy contribution to the world energy production would have to increase by a factor 130 or more, by the end of the century. The dispersed and fluctuating nature of these energy sources also implies an important extension of the electric grid $(50000 \mathrm{~km}$ of new power lines for Europe). Furthermore, when there is no wind and no sun, wind and solar energies are replaced by fossil fuels, often with coal fired power plants, as for instance in Germany, which makes German citizens amongst the biggest polluters in Europe: Germany has one of the highest $\mathrm{CO}_{2}$ emission per capita and the production of one $\mathrm{kWh}$ of electricity releases one of the largest amount of $\mathrm{CO}_{2}$. The planned shutdown of nuclear power plants in that country will only make it worse.

Energy R\&D has to be systematic, without prejudice. Nuclear fission energy, in particular, must not be left out. It produces no $\mathrm{CO}_{2}$, no air pollution such as $\mathrm{NO}_{x}, \mathrm{SO}_{x}$, etc., and it has the potential to provide abundant, base load type of electric energy for many centuries. Furthermore, nuclear fission technology exists and is well understood.

The question that should be asked is: How should nuclear energy be exploited to be acceptable to Society? Where "acceptable" means that shortcomings of the present generation of critical reactors should be avoided: a) accidents such as at Chernobyl, Three Mile Island, or Fukushima; b) waste management (storage up to one million years is the only option developed so far); c) proliferation of nuclear weapons (the uranium fuel cycle was developed for military purpose); d) sustainability (uranium reserves for Pressurized Water Reactors (PWR) will last less than 100 years at the present rate (extracting natural uranium from see water does not seem a realistic option). 


\section{EPJ Web of Conferences}
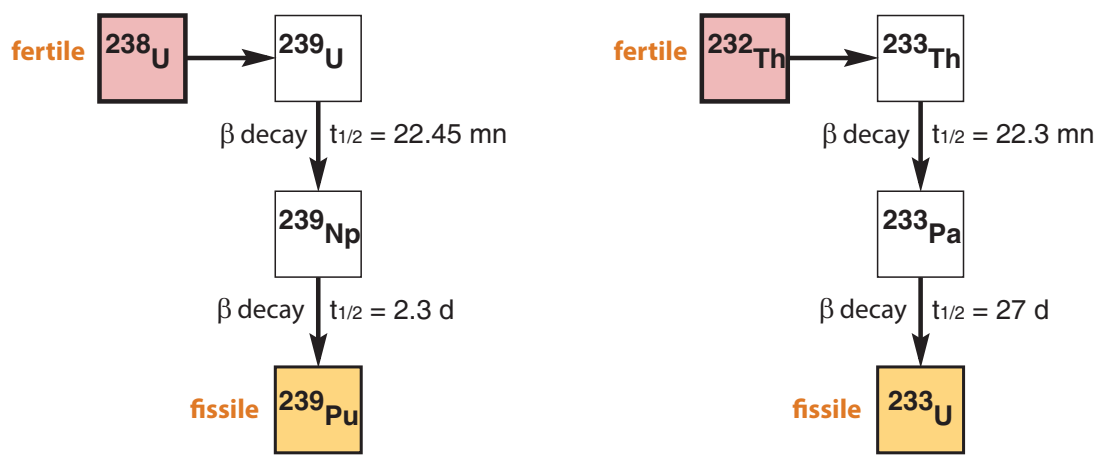

Fig. 2. - Schematics of the ${ }^{239} \mathrm{Pu}$ breeding chain from ${ }^{238} \mathrm{U}$ (left) and of the ${ }^{233} \mathrm{U}$ breeding chain from ${ }^{232} \mathrm{Th}$ (right). Horizontal and vertical arrows indicate neutron captures and $\beta$-decays, respectively.

\section{3. - Thorium}

Thorium is an abundant natural element: $1.2 \times 10^{14}$ tons in the Earth's crust. It is as abundant as lead, and three to four times more abundant than uranium. Recovering only one part per million would provide the present world power consumption of $15 \mathrm{TW}$, for 18000 years. "Thorium is a source of energy essentially sustainable on the human time scale", said Carlo Rubbia [6] at ThEC13.

Isotopically pure, natural thorium $\left({ }^{232} \mathrm{Th}\right)$ has an $\alpha$-decay with a half-life of 14 billion years (almost stable). Thorium occurs in several minerals including thorite, thorianite and monazite and is often a by-product of mining for rare earths.

Known and estimated recoverable resources are between 6.6 and 7.4 million tons according to IAEA [7], which represents about 1000 years of present world energy consumption. These resources are probably underestimated, as thorium has not yet been the object of systematic searches.

\section{4. - Fission energy from thorium}

Thorium is fertile, not fissile, so it can only be used in breeding mode, by producing fissile uranium isotope ${ }^{233} \mathrm{U}$, in a neutron capture and decay chain analogous to that producing plutonium $\left({ }^{239} \mathrm{Pu}\right)$ from the isotope ${ }^{238} \mathrm{U}$ of uranium (fig. 2).

However, breeding uses almost all the thorium adding a factor 140 gain in reserves compared to ${ }^{235} \mathrm{U}$ in PWRs (in addition to the factor of 3 to 4 in natural abundance).

More importantly, the use of thorium minimizes long-lived nuclear waste production. For instance, it takes 7 successive neutron captures to produce ${ }^{239} \mathrm{Pu}$ from ${ }^{232} \mathrm{Th}$ (fig. 3). For similar reasons, the production of minor actinides is highly suppressed. As a consequence, not only thorium minimizes nuclear-waste production, but thorium in a fast neutron flux may also be used to destroy nuclear waste produced by present nuclear 


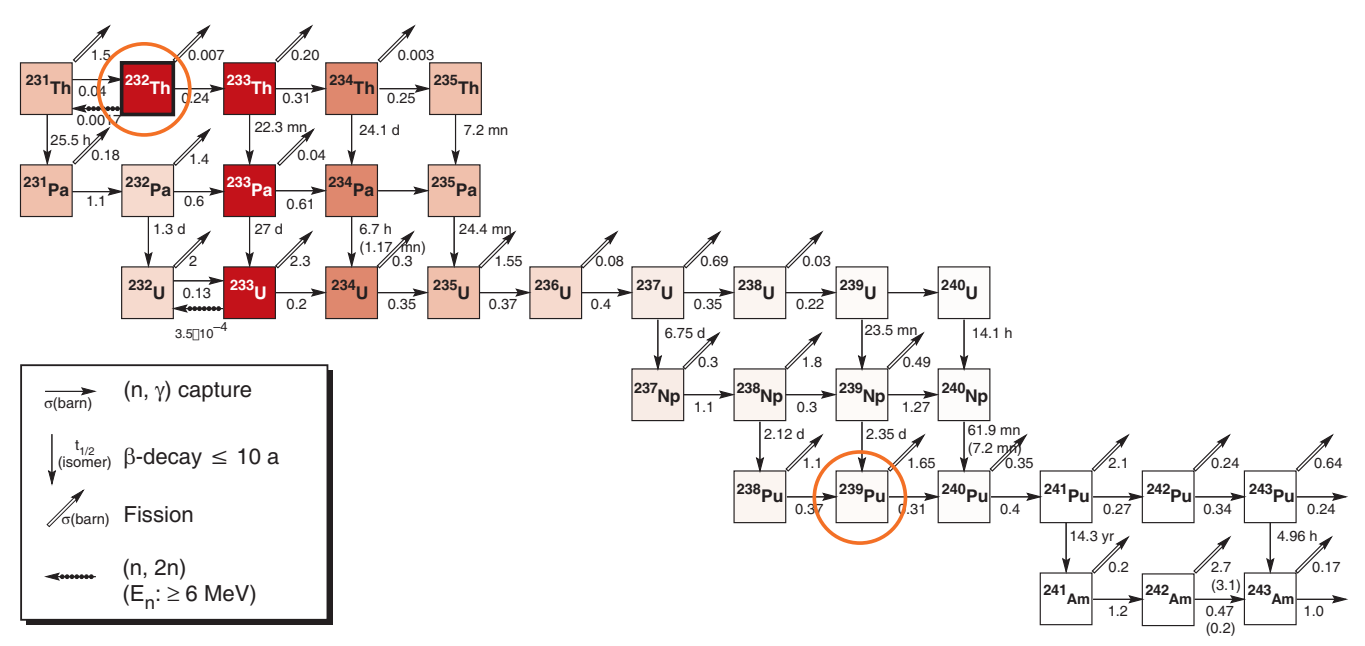

Fig. 3. - Neutron capture, $\beta$-decay and fission chain for natural thorium immersed in a fast neutron flux, showing that the probability of producing ${ }^{239} \mathrm{Pu}$ must be extremely small, as it requires 7 successive neutron captures. This explains why the long-term component of nuclear waste, mainly transuranic elements, is suppressed by several orders of magnitude with thorium, compared to uranium fuel.

power plants. There are other interesting properties of thorium: the high melting point of thorium dioxide, the highest of all oxides and one of the best refractory materials $\left(3300{ }^{\circ} \mathrm{C}\right.$ compared to $2865^{\circ} \mathrm{C}$ for $\left.\mathrm{UO}_{2}\right)$ and the high melting point of metallic thorium $\left(1750{ }^{\circ} \mathrm{C}\right.$ compared to $1130{ }^{\circ} \mathrm{C}$ for metallic uranium).

The thorium fuel cycle has a major advantage over the uranium fuel cycle, in that it is very resistant to the proliferation of nuclear weapons (see for instance [8]).

\section{5. - Why is it challenging to use thorium?}

Firstly, it is necessary to produce (breed) ${ }^{233} \mathrm{U}$ from thorium in some way. Then, thorium mixed with a fissile element cannot be simply substituted to PWR fuel because of neutron inventory issues, mainly due to the larger neutron capture cross-section of thorium (almost three times that of ${ }^{238} \mathrm{U}$ for thermal neutrons) (fig. 4, top) and to the long half-life of the intermediate element, protactinium, $t_{1 / 2}\left({ }^{233} \mathrm{~Pa}\right) \approx 27$ days.

Even though ${ }^{233} \mathrm{U}$ is generally a better fissile element than ${ }^{235} \mathrm{U}$ and ${ }^{239} \mathrm{Pu}$, it is precisely where one would want to use thorium to minimize nuclear waste production, namely in the fast neutron part of the energy spectrum, that ${ }^{239} \mathrm{Pu}$ is somewhat better than ${ }^{233} \mathrm{U}$ (fig. 4, bottom), in terms of breeding. As two neutrons are needed to sustain the chain, breeding requires more than two neutrons. 


\section{EPJ Web of Conferences}
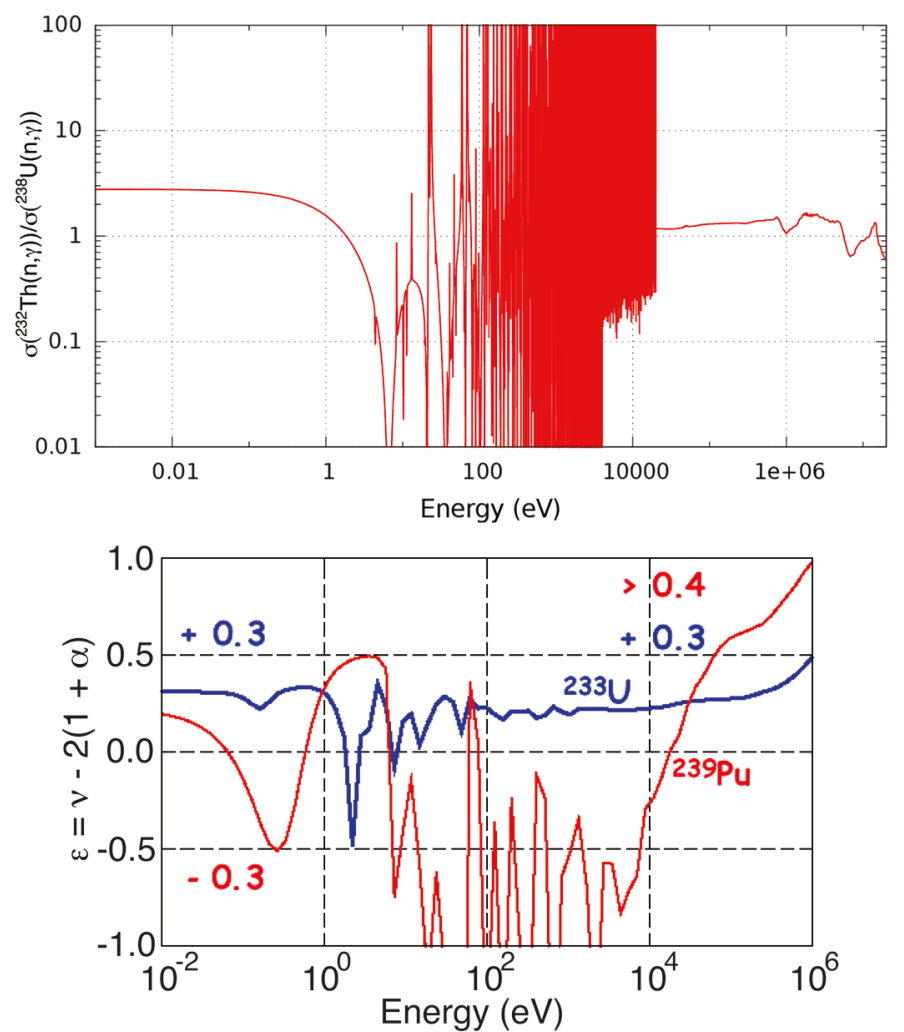

Fig. 4. - Top: Ratio of ${ }^{232} \mathrm{Th}$ to ${ }^{238} \mathrm{U}$ neutron capture cross sections, as a function of neutron energy. Bottom: Comparison as a function of neutron energy of breeding qualities of ${ }^{233} \mathrm{U}$ and ${ }^{239} \mathrm{Pu}$ illustrated by the average number $(\varepsilon)$ of neutrons in excess of the 2 neutrons needed to run the fission chain, where $\nu$ is the number of neutrons per fission, $\alpha=\nu \sigma_{\mathrm{f}} /\left(\sigma_{\mathrm{f}}+\sigma_{\mathrm{c}}\right)$, with $\sigma_{\mathrm{f}}$ and $\sigma_{\mathrm{c}}$ the neutron microscopic fission and capture cross sections, respectively. Breeding is possible when $\varepsilon>0$. One can see that ${ }^{233} \mathrm{U}$ is generally better than ${ }^{239} \mathrm{Pu}$, except in the fast-neutron energy region, above a few tens of $\mathrm{keV}$.

\section{6. - What are the options?}

There are three main options for using thorium:

- Breeding ${ }^{233} \mathrm{U}$ in thorium blankets around critical reactors and then introducing it into advanced thermal or fast critical reactors.

- Continuously recirculating or recycling the burnt fuel after removing accumulated neutron poisons and continuously refuelling the reactor, in order to always have fresh fuel, to guarantee a positive neutron inventory. This is the solution implemented in pebble bed and molten salt critical reactors (fig. 5). 


\section{LNES 2014}
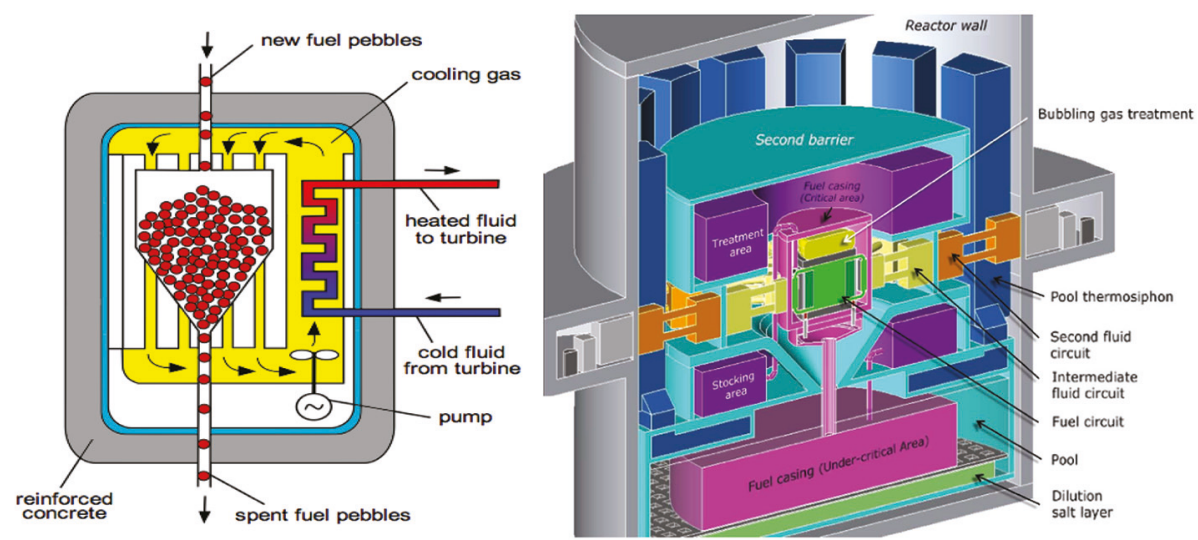

Fig. 5. - Schematics of a pebble bed reactor (left) and of a molten salt reactor (right). Pebble bed reactors are gas cooled. Pebbles made of pyrolytic graphite, containing fissile material usually coated with a ceramic layer of silicon carbide for structural integrity and fission product containment, circulate through the core. In a molten salt reactor the fuel is molten in a salt mixture and fission fragments are extracted on-line in a fuel loop outside the core.

- Using a proton accelerator to provide the excess neutrons needed to sustain the neutron capture and fission chain in a subcritical system (fig. 6, top), and also to burn unwanted nuclear waste. A thorium-based ADS is the solution promoted by iThEC [9].

\section{The Indian Three-Stage Strategy}

India, with little uranium but abundant thorium resources, has the most advanced working scheme for using thorium (including front-end and back-end of the fuel cycle) $[10]$ :

- Use heavy water (CANDU) or light water (LWR) reactors to produce plutonium from India's small uranium supply.

- Use sodium-cooled uranium-plutonium fast reactors with a thorium blanket to breed ${ }^{233} \mathrm{U}$.

- Reprocess blankets and manufacture ${ }^{233}$ U-thorium fuel for advanced thermal or fast critical reactors.

The Indian scheme certainly works from the technical point of view. However, issues remain concerning the complexity of developing and maintaining three nuclear technologies; the sustainability, as it requires uranium in the first stage; and the lack of a solution for the accumulated nuclear waste. 


\section{EPJ Web of Conferences}

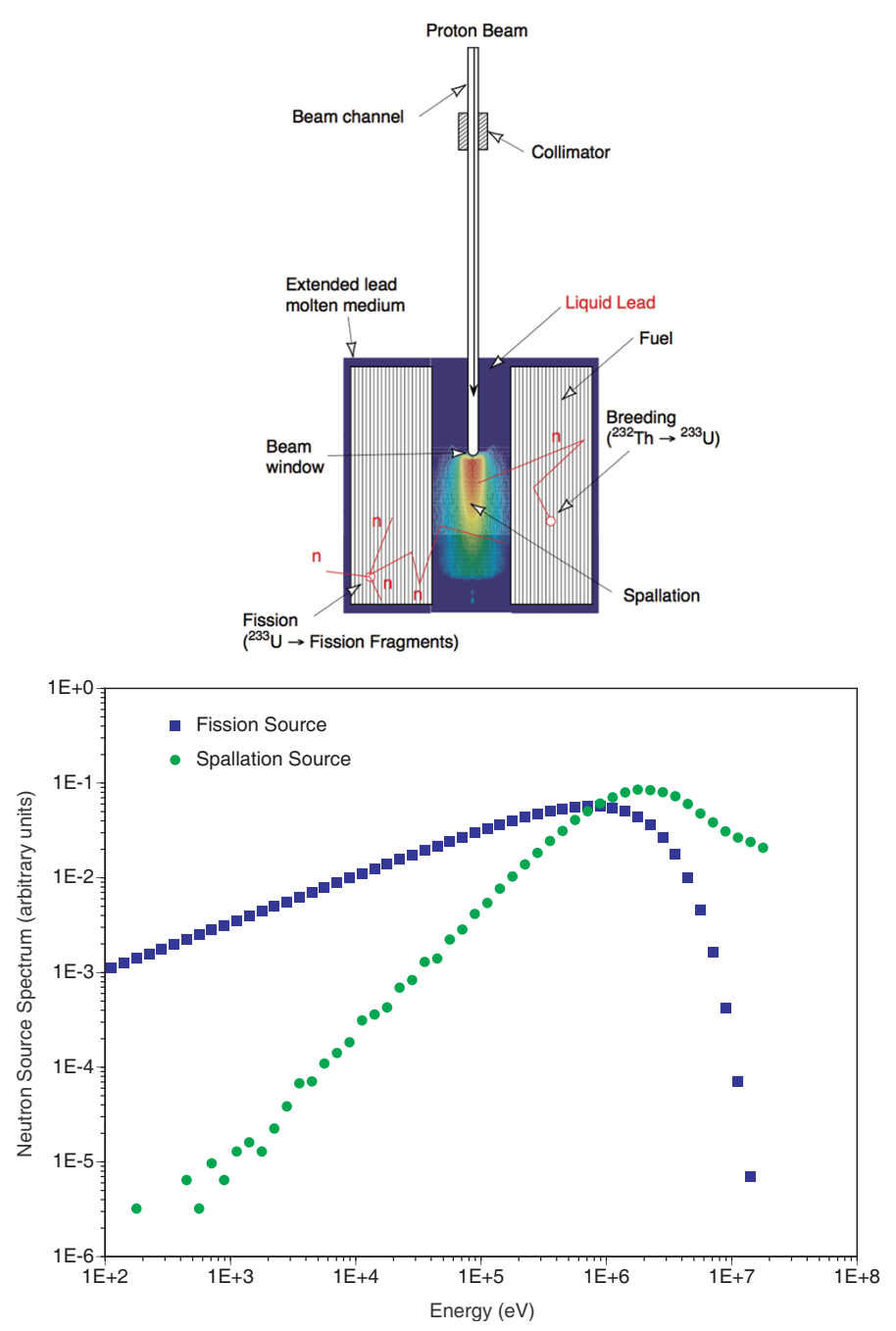

Fig. 6. - Top: Principle of an ADS system showing a proton beam producing neutrons by spallation in a molten lead volume surrounded by a core containing thorium fuel [8]. Bottom: Comparison between fission and spallation neutron energy spectra.

\section{Pebble Bed Critical Reactors}

Farrington Daniels at Oakridge National Laboratory (ONL), in the USA, first proposed pebble bed reactors, in the 1940s. Initial developments took place in Germany (AVR Jülich), followed by the THTR-300 project [11]. Further developments were made in South Africa, the USA, China and Turkey. These are generally graphite-moderated, gas-cooled, high-temperature critical reactors, in which pyrolytic carbon pebbles coated with fireproof silicon carbide containing the fuel circulate through the core. These systems have several drawbacks: 


\section{LNES 2014}

- Passive cooling by natural air convection, a desirable feature, implies no containment in case of accident.

- Water cannot be used for cooling in case of accident.

- Graphite which is used as moderator is flammable.

- The burnup is limited and minor actinides have a small fission probability, as the graphite thermalizes the neutron flux. Pebble bed reactors produce more high-level nuclear waste than current nuclear reactors.

- Fuel handling is delicate, as pebbles are cycled through the reactor. It was an accident in the pebble circulation and instability of the fuel temperature of the AVR that stopped the development in Germany.

- Reliance on highly resistant fuel pebbles makes nuclear waste partitioning and transmutation virtually impossible.

\section{Molten Salt Critical Reactors (MSR)}

This is a technology that is surprisingly concentrating industry's interest world-wide, in China, India, the UK, the USA, the Czech Republic, France, and even Switzerland, at least until recently. MSR were pioneered at ONL in the $1960 \mathrm{~s}$, with the $7.4 \mathrm{MW}_{\text {th }}$ Molten Salt Reactor Experiment, using $\mathrm{UF}_{4}$.

In MSR, the fuel circulates through the core as a high-temperature molten salt mixture, and there is chemistry on-line, in the fuel loop outside the core, to extract fission fragments and eventually protactinium, in order to help the neutron inventory.

The main advantages are: liquid fuel allows the burnup to extend indefinitely, as a result of on-line reprocessing; the heat is produced directly in the heat transfer fluid; the high temperature $\left(500^{\circ} \mathrm{C}-600^{\circ} \mathrm{C}\right)$ is favourable to the conversion of heat into electrical energy; and passive cooling is possible for decay heat removal, after dumping the molten fuel by gravity into a reservoir underneath the core.

There are however important issues: delayed neutron emission occurring outside the core; possible failure of on-line chemistry, which would make it dangerous to re-inject cooler fuel into the core; corrosion with high-temperature salts; the possibility to extract quasi-pure highly proliferating ${ }^{233} \mathrm{~Pa}$; and the resulting delicate licencing issues.

Furthermore, unless salts other than lithium fluoride are developed, these systems will produce a thermal-to-epithermal neutron energy spectrum, which does not favour transmutation of minor actinides.

There is a particularly well-focussed and most ambitious effort in China, at the Shanghai Institute of Applied Physics [12]. At the end of March 2014, the Chinese Government decided that the initial time scale for a first fully functioning thorium MSR reactor should be significantly reduced compared to the 25 years originally considered.

Accelerator-Driven Systems (ADS)

The third and probably the most elegant way of using thorium consists of providing extra neutrons, with an external source, using a proton accelerator. The first use of an 


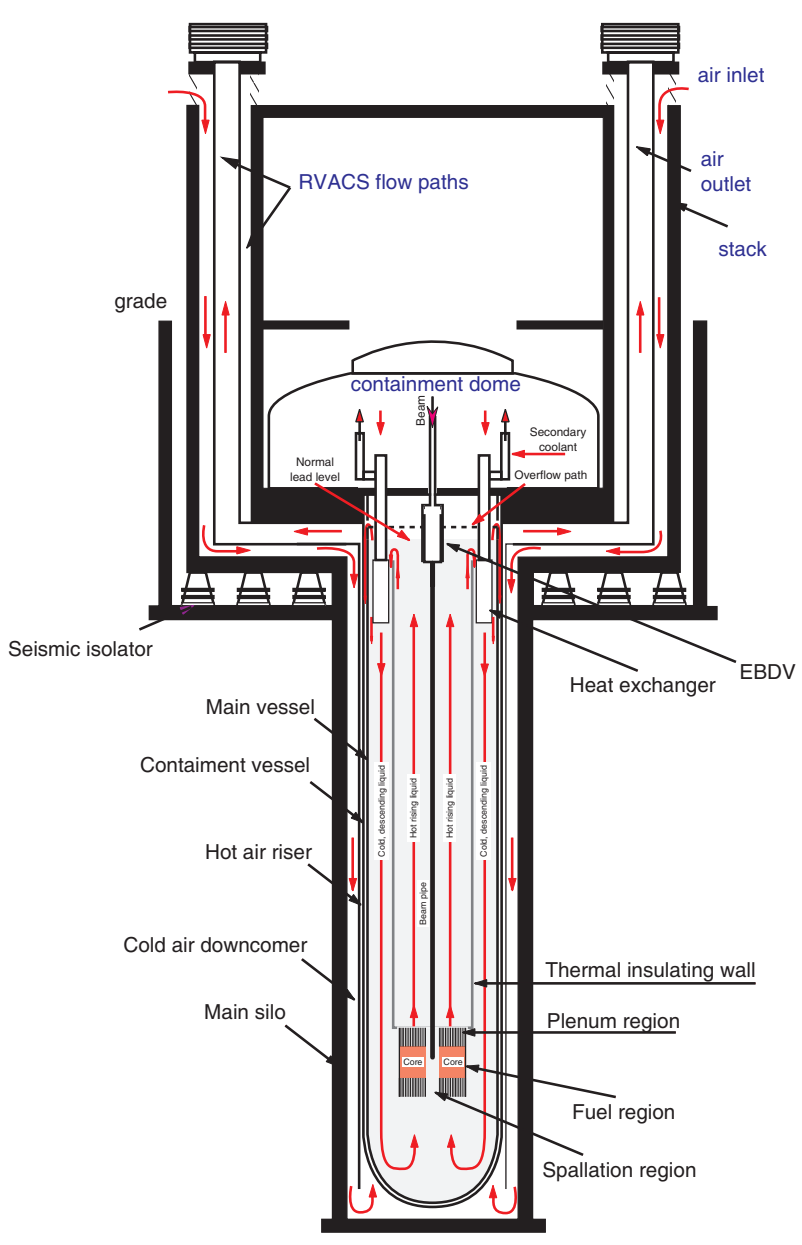

Fig. 7. - Schematic view of an Accelerator-Driven System, the Energy Amplifier, proposed by Carlo Rubbia [8]. The proton beam is inserted vertically, from the top; the spallation process takes place where protons collide with lead at the centre of the fuel core. Natural convection of molten lead is used to extract the heat. This fast neutron system is designed with several passive safety features, as well as with earthquake protections.

accelerator in this context goes back to G. Seaborg who produced the first $\mu \mathrm{g}$ of ${ }^{239} \mathrm{Pu}$, in 1942, with the Berkeley 60 inch cyclotron. In the 1950s, Lawrence's (MTA) and Lewis' ADS projects were dropped or slowed down when rich uranium deposits were discovered in the USA, and it was realized that several hundred $\mathrm{mA}$ of beam intensity, hundreds of MW, would be needed to produce the required beam. No amplification was built into the system, in contrast to today's ADS which only need 1 to $10 \mathrm{MW}$ of beam power.

There was renewed interest in ADS in the 1980s, when the USA decided to slow down the development of fast critical reactors. The Fast Flux Test Facility [13] at Argonne 


\section{LNES 2014}

National Laboratory was shut down by DOE in 1993.

- H. Takahashi at Brookhaven National Laboratory proposed several ADS systems including the idea of burning minor actinides (PHOENIX [14]).

- Ch. D. Bowman at Los Alamos National Laboratory, proposed a thermal neutron ADS [15] for the transmutation of nuclear waste (ATW) using molten thorium fuel and chemistry on-line to extract fission products and ${ }^{233} \mathrm{~Pa}$.

- Japan launched Options for Making Extra Gains from Actinides, OMEGA [16] at JAERI (now JAEA).

In the 1990s, Carlo Rubbia gave a major push to the ADS technology, by launching a vigorous research programme at CERN, based on the development of innovative simulation of nuclear systems, specific experiments to test basic concepts (FEAT [17], TARC [18]), and construction of an advanced neutron Time of Flight facility (n_TOF [19]) to acquire neutron cross-section data, crucial to simulate reliably any configuration with new materials. This resulted in the so-called Energy Amplifier design (fig. 7), as proposed at CERN in the 1990s by C. Rubbia [8].

\section{7. - Advantages of thorium ADS}

Safety

ADS eliminates the possibility of criticality accidents by allowing the system to run in a subcritical mode. Therefore, void coefficient, temperature coefficient, delayed neutron fraction $\beta_{\text {eff }}$ are no longer "critical" parameters. However, subcriticality requires an external neutron source.

As any future generation nuclear system, ADS must be operated with passive safety features. This is especially relevant for emergency cooling to avoid core melt down or limit its consequences, and can be achieved by borrowing for instance from US advanced fast critical reactor designs (RVACS [20]).

ADS will not use dangerous coolants such as liquid sodium foreseen in some Generation IV options [21]. Lead or lead-bismuth eutectic mixtures, are proposed as both target for protons and coolant, guaranteeing a fast neutron spectrum.

\section{Waste Management}

Compared to the uranium once through fuel cycle, the combination of fast neutrons, thorium-based fuel, with recycling of long-lived transuranic actinides (TRU) reduces longlived waste production by several orders of magnitude (fig. 8). It would allow efficient destruction of the long-term component of present stockpile of nuclear waste, the TRU. 


\section{EPJ Web of Conferences}

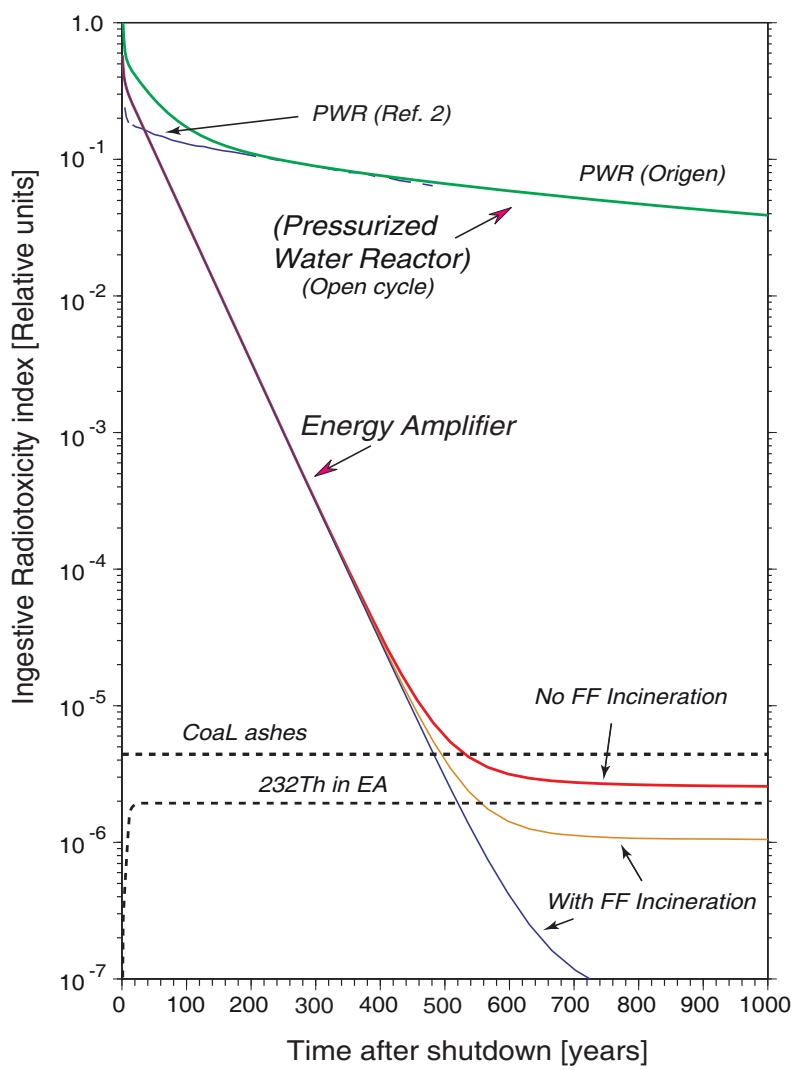

Fig. 8. - Comparison of the time evolutions of the ingestive radio-toxicity of nuclear waste for a PWR (once through cycle), and for an Energy Amplifier [8] with or without destruction of long-lived fission fragments. A comparison is also made with the radio-toxicity of the thorium ore needed to provide the fuel, and the radio-toxicity of coal ashes corresponding to the same energy production (adapted from ref. [8]).

\section{Military Proliferation}

The use of thorium fuel implies insignificant production of neptunium, plutonium and other minor actinides. The uranium extracted from the spent fuel is a mixture of uranium isotopes, with a critical mass of about $28 \mathrm{~kg}$ [8], which implies a strong gamma emission coming from the decay chain of ${ }^{232} \mathrm{U}$, lethal in a $10 \mathrm{mn}$ exposure at less than one meter. Therefore, it would be extremely difficult, practically impossible, to manufacture a bomb with such mixture.

In the re-processing of spent nuclear fuel in a fast neutron ADS, it is not necessary to separate out plutonium as is done in PUREX [22]. Therefore, the pyro-electrolysis method could be used to extract the entire TRU mixture to manufacture fresh thoriumbased fuel, unlike what is currently done with MOX fuel in France, where only plutonium is recycled. 


\section{LNES 2014}

\section{8. - Basic properties of subcritical systems}

The theory of subcritical systems is interesting in itself, to get insight into their physical properties, which are quite different from those of critical systems. In particular, their response to fast reactivity changes is spectacularly more moderate than for critical systems. The knowledge of the neutron flux geometry is important for calculating the generated power distribution and the uniformity of fuel burnup. Even though, with Monte Carlo methods, it is nowadays possible to simulate precisely extremely complex systems, an analytical approach may be used with some simplified assumptions to extract the general properties of such systems and compare them with critical systems (see for instance $[23,24])$.

If one assumes a finite system, with uniform material distribution, monoenergetic neutrons, and small absorption, such system can be represented by a simple equation, similar to that describing a critical system, but with in addition an external neutron source term, representing neutrons provided by the accelerator:

$$
\frac{\partial n(\vec{r}, t)}{\partial t}=\nu \Sigma_{\mathrm{f}} \Phi(\vec{r}, t)+C(\vec{r}, t)-\Sigma_{a} \Phi(\vec{r}, t)+D \nabla^{2} \Phi(\vec{r}, t)
$$

The rate of change of $n$, the number of neutrons, as a function of space $(\vec{r})$ and time $(t)$ is given by the difference between the rate of neutrons provided by fissions and by the accelerator and the rate of neutrons lost by absorption (fission and capture) and by leakage outside the geometrical volume considered. In the above equation, $\nu$ is the number of neutrons produced per fission, $\Sigma_{\mathrm{f}}$ and $\Sigma_{a}$ are the neutron fission and absorption macroscopic cross sections, $\Phi$ is the neutron flux, $C$ is the spallation neutron source term, $D$ is the neutron diffusion coefficient, and $\nabla^{2}$ is the Laplacian. It is interesting to consider such system at equilibrium:

$$
\frac{\partial n(\vec{r}, t)}{\partial t}=0 \Rightarrow \nabla^{2} \Phi(\vec{r}, t)+\frac{\left(k_{\infty}-1\right)}{L_{C}^{2}} \Phi(\vec{r}, t)=-\frac{C}{D}
$$

with $k_{\infty} \equiv \frac{\nu \Sigma_{\mathrm{f}}}{\Sigma_{a}}$ and where $L_{C}$, the neutron diffusion length, is given by $L_{C}^{2} \equiv \frac{D}{\Sigma_{a}}$. There are two very different regimes corresponding to the two possible signs of $k_{\infty}-1$ :

$-k_{\infty}<1$, the system is intrinsically subcritical, as was the case of the FEAT experiment [17] at CERN, with $k_{\infty} \approx 0.93$. The solution is an exponential function (fig. 9).

$-k_{\infty}>1$, the subcriticality of the system comes from the lack of neutron confinement, it is a geometrical issue. The solution is oscillatory. This is for instance the case of Carlo Rubbia's Energy Amplifier, with $k_{\infty} \approx 1.2-1.3$. In this case, one can expand the neutron external source term and the neutron flux function, over the complete set of solutions $\left(\psi_{l, m, n}\right)$ of the kernel equation:

$$
\nabla^{2} \Phi(\vec{r}, t)+B^{2} \Phi(\vec{r}, t)=0 ; \quad B^{2} \equiv \frac{\left(k_{\infty}-1\right)}{L_{C}^{2}}
$$




\section{EPJ Web of Conferences}

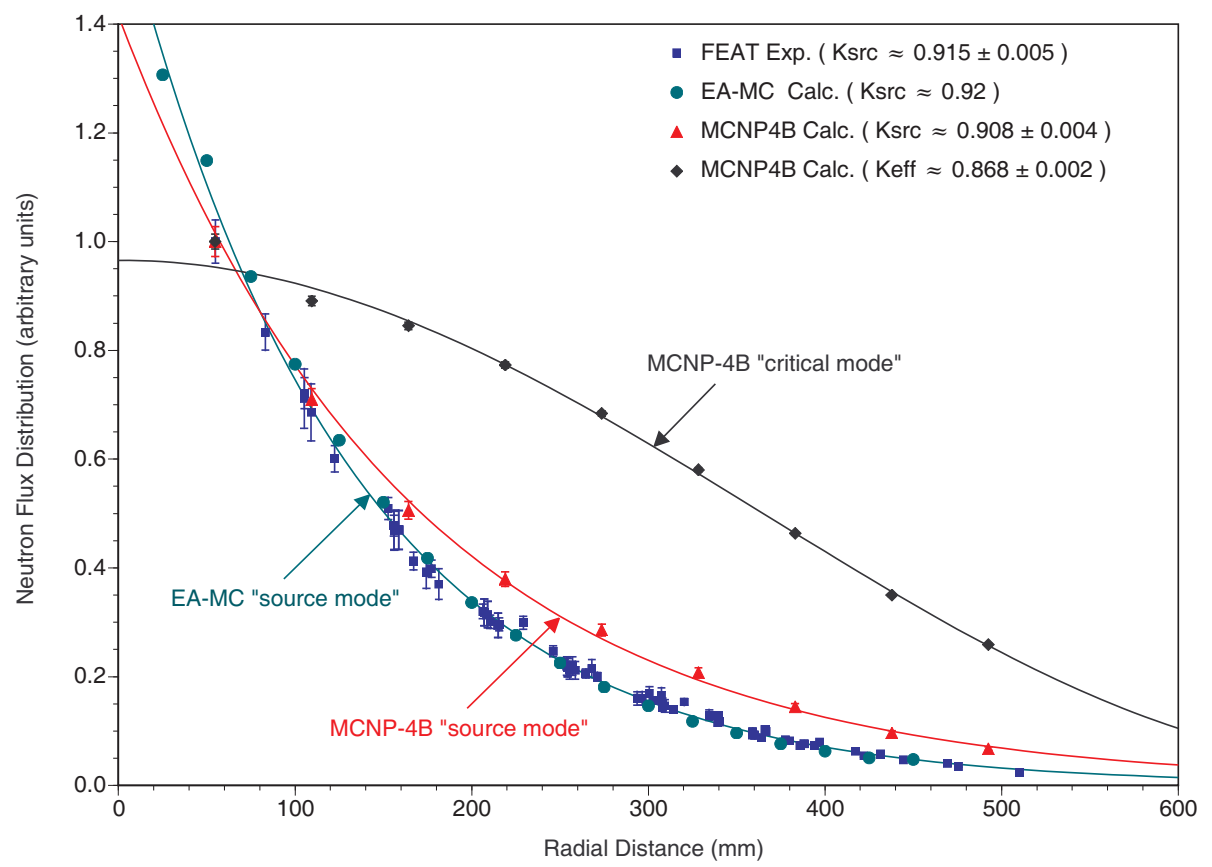

Fig. 9. - Neutron flux measured in the FEAT experiment [17], as a function of the radial distance to the beam line, compared to various Monte Carlo simulations, illustrating the exponential behaviour of a solution to the flux equation with $k_{\infty}<1$.

Defining the expansion coefficients in the following way:

$$
C(\vec{r})=D \sum_{l, m, n} C_{l, m, n} \psi_{l, m, n}(\vec{r}) ; \quad \Phi(\vec{r})=\sum_{l, m, n} \Phi_{l, m, n} \psi_{l, m, n}(\vec{r}),
$$

one obtains the general solution for the neutron flux, upon substitution of the above expressions into the equilibrium equation:

$$
\Phi(\vec{r})=L_{C}^{2} \sum_{l, m, n} \frac{C_{l, m, n}}{1-k_{l, m, n}} \psi_{l, m, n}(\vec{r}) ; \quad k_{l, m, n} \equiv k_{\infty}-L_{C}^{2} B_{l, m, n}^{2}
$$

where $B_{l, m, n}^{2}$ are the eigenvalues corresponding to the eigenfunctions $\left(\psi_{l, m, n}\right)$. Unlike critical systems of which only the fundamental mode exists, in the ADS case, all the modes are excited, and a general theorem can be proven: if the fundamental mode is subcritical, then all the other modes are also subcritical. This is obviously an important and reassuring property of subcritical systems.

A unique property of subcritical systems is that the neutron multiplication factor changes whether the accelerator is on $\left(k_{\mathrm{s}} \equiv k_{\text {source }}\right)$ or off $\left(k_{\text {eff }}\right)$. When the accelerator is off, the definition of neutron multiplication coefficient is similar to that of a critical 


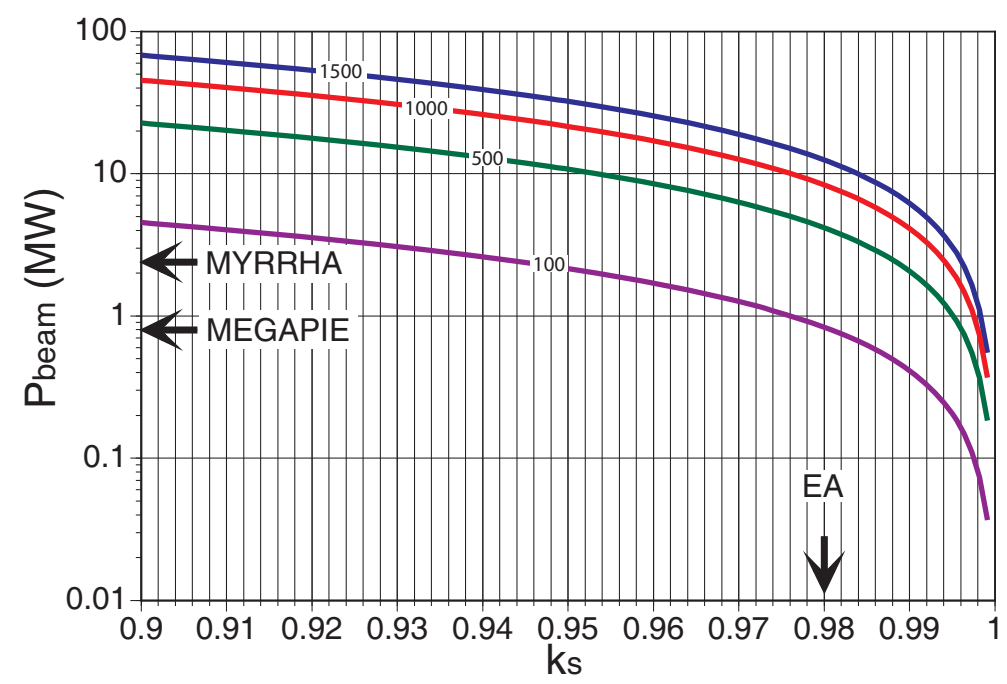

Fig. 10. - Beam power versus $k_{\mathrm{s}}$. Curves of constant fission power are shown, labelled in $\mathrm{MW}_{\mathrm{th}}$. The $k_{\mathrm{s}}$ value for C. Rubbia's Energy Amplifier [8] is indicated, as well as the beam power achieved with MEGAPIE [27] and that planned for MYRRHA [26].

system:

$$
k_{\mathrm{eff}} \equiv \frac{\nu \Sigma_{\mathrm{f}}}{\Sigma_{a}+D B^{2}} .
$$

However, when the accelerator is on, the presence of the external source term and of non-fission neutron multiplication due in part to the hard energy spectrum of spallation neutrons (fig. 6 , bottom), through ( $\mathrm{n}, \mathrm{Xn}$ ) reactions on lead, modifies the neutron multiplication coefficient:

$$
k_{\mathrm{s}}=k_{\mathrm{eff}}+\Delta k, \quad \text { with } \quad \Delta k>0
$$

The change of geometry of the neutron flux between the fundamental mode characterizing $k_{\text {eff }}$ and all the modes excited by the source, characterizing $k_{\mathrm{s}}$, also plays a role. As a consequence, the good news is that $k_{\mathrm{s}}$ is always larger than $k_{\text {eff }}$, which means that switching off the accelerator, hence the neutron source, not only stops the main power generation, but also moves the system further away from prompt criticality, back to the $k_{\text {eff }}$ value. This is a major safety asset for ADS.

Accelerators for ADS

The required accelerator power $\left(P_{\text {beam }}\right)$ can be expressed as a function of the desired ADS fission power $\left(P_{\mathrm{ADS}}\right)$, the neutron multiplication coefficient $k_{\mathrm{s}}$, and $G_{0}$, a constant that depends on the beam energy, the target material and the detailed geometry of the 


\section{EPJ Web of Conferences}

system:

$$
P_{\text {beam }}=\frac{\left(1-k_{\mathrm{s}}\right)}{k_{\mathrm{S}} G_{0}} P_{\mathrm{ADS}}
$$

Therefore, the choice of the accelerator power is a trade-off between accelerator power and criticality margin (fig. 10). For given $k_{\mathrm{s}}$ and $G_{0}$ values, the ADS power changes linearly with the beam power, allowing the possibility of modulating the power output with the accelerator. This could be a useful feature if ADS systems were to be associated with fluctuating renewable energy sources.

Compared to uranium, neutronics with thorium is very favourable to power modulation because of the much longer half-life of ${ }^{233} \mathrm{~Pa}(27 \mathrm{~d})$ compared to ${ }^{239} \mathrm{~Np}$ (2.3d). What is a problem with the use of thorium in critical reactors becomes an advantage in the case of ADS.

The Paul Scherrer Institute (PSI) separate-turns cyclotron [25] achieved a beam power of $1.4 \mathrm{MW}(2.4 \mathrm{~mA}$, with $0.59 \mathrm{GeV}$ protons). This beam could already produce, a power $P_{\mathrm{ADS}}=210 \mathrm{MW}_{\text {th }}$ with $k_{\mathrm{s}}=0.98$, in an Energy Amplifier, as designed by C. Rubbia [8].

Accelerator requirements for $A D S$

In principle, it does not matter how the external neutron source is provided. In practice, for industrial applications, there are a number of well-defined requirements for the accelerator:

Beam particle: The preferred choice is protons for their simplicity of production and because they are most efficient in producing neutrons by spallation.

Beam Energy: Optimum neutron production is obtained for $E_{\text {beam }} \geq 900 \mathrm{MeV}$. At lower energy, protons tend to loose energy by ionization, which does not produce neutrons. Above $900 \mathrm{GeV}$, there is an energy gain plateau, as shown by the FEAT experiment [17], slowly decreasing with increasing energy, as pion production increases.

Beam power: Typically 1 to $10 \mathrm{MW}$ depending on the choice of $k_{\mathrm{s}}$ value, and on the desired power output. A large operational range of beam intensities might be required to follow electrical power demand. The maximum range will depend on the core design. Beam power stability is obviously important, as a $1 \%$ fluctuation of beam intensity causes a $1 \%$ fluctuation of the thermal power.

Beam spot size (footprint): Should be large at impact on the window separating the vacuum chamber from the target (studies at JAEA have shown that densities of up to $0.1-0.2 \mathrm{~mA} / \mathrm{cm}^{2}$ can be withstood today). For MYRRHA [26] the design value is $0.07 \mathrm{~mA} / \mathrm{cm}^{2}$.

Beam losses: They have to be controlled such as to minimize irradiation of the accelerator elements and of the environment. The figure of merit is $1 \mathrm{~W} / \mathrm{m}$ for LINACs, while beam losses are localized for cyclotrons. Beam losses are a main issue for any high power beam, not only for ADS. They have direct impact on maintenance and repair.

Reliability: Fatigue of mechanical structures, in particular of fuel elements, requires the minimization of beam trips. For instance, for MYRRHA, there are no constraints on 
the number of trips of duration of less than $0.1 \mathrm{~s}$. However, no more than 100 trips per day with $0.1 \mathrm{~s}<T_{\text {trip }}<3 \mathrm{~s}$, and 10 trips in three months with $T_{\text {trip }}>3 \mathrm{~s}$ are allowed [26].

Energy efficiency: One must maximize the accelerator electric power efficiency, $\eta \equiv$ $P_{\text {beam }} / P_{\text {grid }}$. This is relevant to the overall energy efficiency of the system.

Size of accelerator: This might be a feature in favour of cyclotrons, since for nuclear waste elimination, one might want the accelerator to fit within the site of a nuclear power plant, to avoid transportation of waste.

Cost: This is obviously a very important element to be taken into account.

In the end, the solution chosen among LINAC, Cyclotron or FFAG technologies, will be the one best fulfilling all of the above requirements.

To conclude, one main criticism of ADS has been that "the accelerator does not exist and will be too expensive", this is obviously a challenge to take on by the accelerator community.

\section{ADS Developments}

Even though R\&D on ADS is certainly not at the level required by the importance of the energy issue, a significant R\&D effort is taking place, worldwide.

The PSI cyclotron beam has already reached the power range of industrial applications. MEGAPIE [27], a spallation target ran successfully for three months at SINQ, the Swiss Spallation Neutron Source, at a power of 0.8 MW. SNS, the US Spallation Neutron Source [28], is running at ONL, at 1.4 MW.

The MYRRHA project at SCK•CEN, Mol, Belgium, could be the first ADS prototype of significant power, if funded. It will use a LINAC $(\leq 4 \mathrm{~mA}$ and $\leq 2.4 \mathrm{MW}$, with $0.6 \mathrm{GeV}$ protons), but unfortunately thorium is not on the agenda, and the system will be transformed into a critical research reactor after only a few years of operation as an ADS.

At Troitsk [29] in Russia and at the Institute of Modern Physics in China (CADS) [30] ADS is considered for burning minor actinides, and a discussion in India is taking place to use ADS to simplify the Indian thorium utilization scheme.

Japan recently re-launched the Transmutation Experimental Facility program at JPARC, which is now part of the roadmap toward the ADS proposed by JAEA for nuclear waste transmutation and consists of two activities, under JPARC:

- Development of the ADS Target Test Facility (TEF-T) to verify the feasibility of the beam window, which is a challenge for ADS and to consider it as a material test facility;

- Further development of the Transmutation Physics Experimental Facility (TEF-P) to overcome difficulties in reactor physics issues such as subcritical core and a minor actinide loaded core.

There are other new ideas, which were presented at the ThEC13 conference: Molten Salt ADS by C. Rubbia [6], C. Pyeon (Japan) [31], and J-S Chai (Korea) [32]. The idea of using a molten salt either to obtain molten fuel as in MSR or simply as a coolant could help relax requirements on the accelerator in terms of number of power trips. It allows in principle to work at higher temperatures, which increases the electrical conversion 


\section{EPJ Web of Conferences}

efficiency. There are also relevant studies of corrosion with high temperature lead or leadbismuth eutectic mixture, material compatibility, which have resulted in the production of new material resistant to corrosion in lead up to about $550{ }^{\circ} \mathrm{C}$. For instance, reduced activation ferritic martensitic steels, which also have applications in fusion technologies.

\section{9. - Destruction of nuclear waste}

The radio-toxicity of the waste produced by an ADS using thorium fuel can be reduced to a level of the order of the radio-toxicity level of coal ashes corresponding to the same energy production or of the thorium ore used to manufacture the fuel, or even smaller if long-lived fission fragments (mainly ${ }^{99} \mathrm{Tc}$ and ${ }^{129} \mathrm{I}$ ) are also transmuted [18] (fig. 8). ADS associated to thorium fuel is the only practical way known today of destroying minor actinides, a component of long-lived nuclear waste. Plutonium could also be destroyed efficiently as shown by C. Rubbia, for instance in the case of Spain [33] for civil plutonium, or for military plutonium. According to the simulation validated by the FEAT [17] and TARC [18] experiments, an ADS, such as an Energy Amplifier, could destroy three times the amount of waste produced by a PWR running at the same thermal power [8]. With an ADS, destruction of plutonium and of minor actinides by fission releases energy that can produce electricity, thereby minimizing the cost of destroying nuclear waste.

\section{0. - Conclusion}

The energy problem is too important not to explore systematically all options for the development of abundant, clean and safe energy sources. There is no reason to keep nuclear energy based on thorium out of the energy R\&D effort. Developed countries, which already master the technological know-how, should play the leading role [34].

The physics of Accelerator-Driven Systems is entirely understood. Conceptual designs exist. The next step is a prototype of significant power to validate technological solutions and to learn how to operate such systems.

When taking into account the need for safety, proper waste management and nonproliferation, thorium in a fast neutron ADS is a most promising option for energy production and waste elimination.

Our society cannot afford not to explore systematically all possibilities to develop the energy sources, which should be available as soon as possible, to replace fossil fuels.

\section{REFERENCES}

[1] BP Statistical Review of World Energy 2013.

[2] Tripati Aradhna K. et al., Coupling of $\mathrm{CO}_{2}$ and Ice Sheet Stability Over Major Climate Transitions of the Last 20 Million Years, Science, 326 (2009) 1394; DOI: 10.1126/science.1178296.

[3] IPCC, Fifth Assessment Report, Climate change 2014.

[4] Health and Environment Alliance, "The Unpaid Health Bill", 2013 Report.

[5] WHO Report, March 25, 2014. 
[6] RubBia C., "A future for thorium power?", in Proceedings of the ThEC13 Conference, Oct. 27-31, 2013, Geneva, Switzerland (Springer) to be published.

[7] Tulsidas Harikrishnan, Nuclear Fuel Cycle and Materials Section, International Atomic Energy Agency, Thorium reserves in the world.

[8] Rubbia C. et al., "Conceptual Design of a Fast Neutron Operated High Power Energy Amplifier", CERN/AT/95-44 (ET), Sept. 29, 1995; see also RubBia C., "A High Gain Energy Amplifier Operated with fast Neutrons", in Int. Conf. on ADT Technologies and Applications, Las Vegas, AIP Conf. Proc. 346, 1994.

[9] International Thorium Energy Committee (iThEC), 17 rue François-Dussaud, 1227 Acacias-Geneva, Switzerland (www.iThEC.org).

[10] Vijayan P. K., "Overview of the Thorium Programme in India", in Proceedings of the ThEC13 Conference, Oct. 27-31, 2013, Geneva, Switzerland (Springer) to be published.

[11] THTR-300, see for instance www.thtr.de.

[12] Xu Honguie, "Thorium Energy R\&D in China", in Proceedings of the ThEC13 Conference, Oct. 27-31, 2013, Geneva, Switzerland (Springer) to be published.

[13] "A Summary Description of the Fast Flux Test Facility", compiled by Cabell C. P., Hanford Engineering Development Laboratory, Report HEDL-400, December 1980.

[14] Vantuyle G. J., Takahashi H., Todosow M., Aronson A. L, Slovik G. C. and HoraK W. C., "The PHOENIX Concept", BNL—52279, DE91 011519.

[15] Bowman C. et al., Nucl. Instrum. Methods, A, 320 (1992) 336.

[16] Mukaiyama, Takehiko, "OMEGA Program in Japan and ADS development at JAERI", in ADTTA '99 - 3rd International Conference on Accelerator Driven Transmutation Techniques and Applications, 7-11 Jun 1999, Prague, Czech Republic, CNUM: C99-0607.10 .

[17] Andriamonje S. et al., Phys. Lett. B, 348 (1995) 697.

[18] Abánades A. et al., Nucl. Instrum. Methods Phys. Res. A, 478 (2002) 577.

[19] Rubbia C. et al., "A High Resolution Spallation Driven Facility at the CERN-PS to Measure Neutron Cross Sections in the Interval from $1 \mathrm{eV}$ to $250 \mathrm{MeV}$ ", CERN/LHC/9802 (EET), May 30, 1998; "A High Resolution Spallation Driven Facility at the CERNPS to Measure Neutron Cross Sections in the Interval from $1 \mathrm{eV}$ to $250 \mathrm{MeV}$ : A Relative Performance Assessment", CERN/LHC/98-02 (EET)-add. 1, June 15, 1998; Abramovich S. et al., "Proposal for a Neutron Time of Flight Facility", CERN/SPSC 99-8, SPSC/P 310, 17 March 1999.

[20] See for instance H. Alter, p. 2 in "Specialists' Meeting on Decay Heat removal and Natural Convection in LMFBRs", BNL (1985) and additional information in the same Proceedings.

[21] See for instance the European Nuclear Society at www.euronuclear.org/1-information/ generation-IV.htm.

[22] See for instance the European Nuclear Society at www.euronuclear.org/info/ encyclopedia/p/purex-process.htm.

[23] Rubbia C., "An analytical approach to the Energy Amplifier", CERN/AT/ET/Internal Note 94-036.

[24] Revol J.-P., "Analytical Study of the Energy Amplifier Microscopic Physics", CERN/AT/ET Internal Note 95-025/Rev.1.

[25] Paul Scherrer Institut (PSI), 5232 Villigen, Switzerland (www.psi.ch).

[26] Abderrahim Hamid Aїт, "MYRRHA, a Flexible and Fast Spectrum Irradiation Facility", in Proceedings of the ThEC13 Conference, Oct. 27-31, 2013, Geneva, Switzerland (Springer) to be published.

[27] LAtGÉ CH., "MEGAPIE, the World's first high-power liquid metal spallation neutron source", in Proceedings of the ThEC13 Conference, Oct. 27-31, 2013, Geneva, Switzerland (Springer) to be published. 


\section{EPJ Web of Conferences}

[28] SNS, see for instance www.neutrons.ornl.gov/facilities/SNS.

[29] Sidorkin S. F., "The Troisk ADS Project", in Proceedings of the ThEC13 Conference, Oct. 27-31, 2013, Geneva, Switzerland (Springer) to be published.

[30] Lei YAnG, "Current Status of CADS", in Proceedings of the ThEC13 Conference, Oct. 27-31, 2013, Geneva, Switzerland (Springer) to be published.

[31] Pyeon C., in Proceedings of the ThEC13 Conference, Oct. 27-31, 2013, Geneva, Switzerland (Springer) to be published.

[32] Chai J.-S., in Proceedings of the ThEC13 Conference, Oct. 27-31, 2013, Geneva, Switzerland (Springer) to be published.

[33] Rubbia C., Buono S., Kadi Y. and Rubio J. A., "Fast Neutron Incineration in the Energy Amplifier as Alternative to Geological Storage: the Case of Spain", CERN/LHC/97-01 (EET).

[34] Revol J.-P., "The Thorium Solution", Pan European Networks: Government 09, p. 84-85, February 2014. 